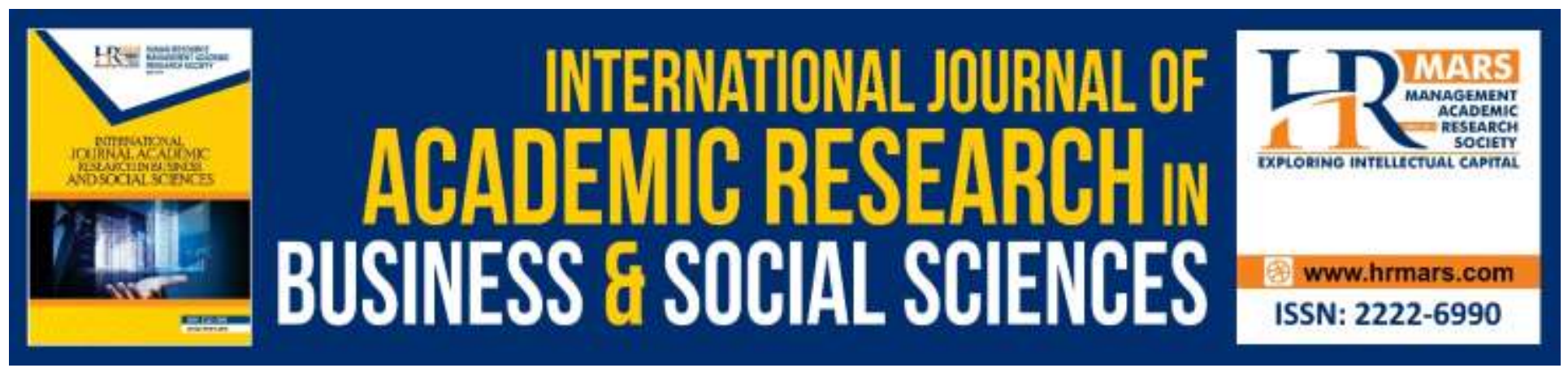

\title{
Self-Prevention of Elderly Migrants Moving into Urban Areas
}

\section{Ittipong Thongsrikate, Dusadee Ayuwat, and Saowalak Chaytaweep}

To Link this Article: http://dx.doi.org/10.6007/IJARBSS/v10-i14/7358

DOI:10.6007/IJARBSS/v10-i14/7358

Received: 17 April 2020, Revised: 20 May 2020, Accepted: 12 June 2020

Published Online: 29 June 2020

In-Text Citation: (Thongsrikate et al., 2020)

To Cite this Article: Thongsrikate, I., Ayuwat, D., \& Chaytaweep, S. (2020). Self-Prevention of Elderly Migrants Moving into Urban Areas. International Journal of Academic Research in Business and Social Sciences, 10(14), 11-22.

Copyright: @ 2020 The Author(s)

Published by Human Resource Management Academic Research Society (www.hrmars.com)

This article is published under the Creative Commons Attribution (CC BY 4.0) license. Anyone may reproduce, distribute, translate and create derivative works of this article (for both commercial and non-commercial purposes), subject to full attribution to the original publication and authors. The full terms of this license may be seen

at: http://creativecommons.org/licences/by/4.0/legalcode

Special Issue: WSTI2018 - Issues and Trends on Education, Science and Technology, 2020, Pg. 11 - 22

http://hrmars.com/index.php/pages/detail/IJARBSS

JOURNAL HOMEPAGE

Full Terms \& Conditions of access and use can be found at

http://hrmars.com/index.php/pages/detail/publication-ethics 


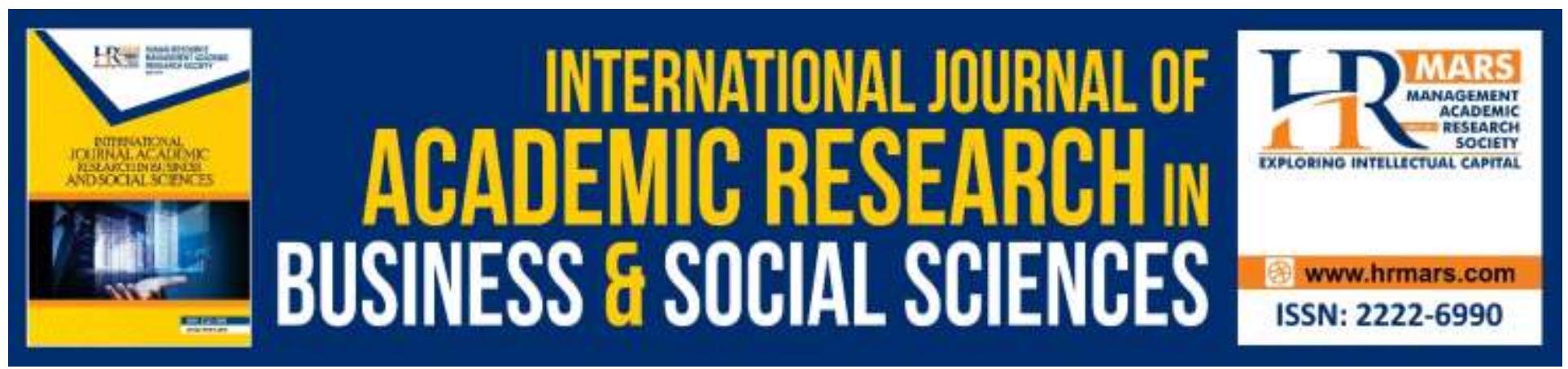

\title{
Self-Prevention of Elderly Migrants Moving into Urban Areas
}

\author{
Ittipong Thongsrikate ${ }^{1}$, Dusadee Ayuwat ${ }^{2}$, and Saowalak \\ Chaytaweep ${ }^{3}$ \\ 1,2Department of Sociology and Anthropology, Faculty of Humanities and Social Science, \\ KhonKaen University, Thailand, ${ }^{3}$ Department of Interdisciplinary of Social Science Studies, Faculty of \\ Liberal Arts, Maejo University, Thailand \\ Email: thongsrikatei@gmail.com
}

\begin{abstract}
This paper investigates the self-prevention of elderly migrants, who move to the urban area of Khon Kaen province, which is one of rapid growth city of Thailand. The study employed a qualitative research, specifically narrative approach. In-depth interview with 16 elderly migrants who have in the urban area of Khon Kaen province. The period of the data collection was August 2017 and data analysis was thematic analysis. The findings indicated that four types of self-prevention; (i)denial of the transition to old age and refusal to be a dependent elderly (ii) perceiving by physical limitation(iii) life goal changing and (iv) anti-fear.
\end{abstract}

Keywords: Adaptation, Elderly Migrants, Self-Prevention.

\section{Introduction}

In the twenty first century, many countries around the world are facing the issue of an increase in the numbers of older people and the spread of urbanization (United Nations, 2002). Thailand is a country that has more than 10 percent of its population considered to be of old age, it has been referred to as an ageing society since 2010 . The national statistical office showed that the elderly accounted for 14.9 percent of Thailand's populationin 2014 (National Statistical Office, 2015). Furthermore, it is predicted that Thailand will officiallybecome an aged societyin 2021 when one fifth of the population will bethe elderly (The National Economic and Social Development Board, 2016) and it will eventually become a super-aged society (Foundation of TGRI, 2013). Moreover, the direction of demography and social science tends to focus on the quality of population in various dimensions (Chimmamee, 2014).

Thai society will become the perfect aged societywhen the population of those more than 60 years old accounts for19.8percent of the total population. The government and relative agencies have attempted to address this from the start of national economic and social development plan, vol.11, aimedto support the elders to be theable to manage themselves and apply their potential to be of benefit and to decrease the dependency ratio of elderly families. However, the national 
economic and social development plan, vol.12emphasizes that the population structure changesthe risks affecting the quality of life (NESDB, 2016). Specifically, we face an aging society that affects the workforce and elderly health, so there is a determination to prepare the workforce to support the population potential at all ages. It is a strategy for supporting and developing human capital.

Migration is an important process of demography in terms of the economic, social, and cultural life of the migrant (Lee, 1966). The study of elderly migrants was not prevalent, compared to the study of other age levels. Most studies of migration are aimed at of people who are working age migration and student migration (Koschasan, 2014). While previous research explores foreign people moving into Thailand, there is little research about elderly migrating within Thailand(Duangkaew, 2015).The stud of the elderly migration is limited because some people believethat the elderlypeople are comfortable in the places and surrounding environments where they have lived since they were born (Porapakkham and Atibobhi, 2000).

Nevertheless, a migration report indicated that elderly migration was at $2 \%$ in 2011 and increased to $2.8 \%$ in 2015 (NSO, 2016). In addition, the migration pattern of the elderly people is to move from a rural area to an urban area, that is to saythere is a social change from an agricultural society to an industrial society (Lee, 1966). The report of a survey ofthe elderly in Thailand by the national statistical office (2014) demonstrated that the proportion of the elderly in urban areas and rural areas was similar, at $40.9 \%$ urban and $59.1 \%$ rural. There was a possibility that older persons would move into the urban areas because of accessibility to public health and welfare services (Foundation of TGRI, 2013).

Moreover, migration affects upon the lifestyle of the migrants (Jampaklay, 2013). The elderly migrants changed themselves; they adopted a new lifestyle and changed their roles in the household (Pprasartkul, 2000; Kaplan et al., 1977). Contributed elderly migrants themselves less and under the household member care. Wireless freedom to manage themselves or become a family-dependence. Interestingly the living conditions of the elderly living in the rural and urban areas of Thailand are different and are related to their happiness (Liamputtong, 2014). Migration to the elderly loses social relations that existed in the origin area. They have to feel the fear of living in a new environment is urban. Including the roles, responsibilities have decreased and changed daily. In order to keep ourselves in an unfamiliar environment and reduce anxiety occurred within the mind, what the elderly you will have to practice is the adaptation.

This paper's interest is self-prevention which the elderly migrants used in order to live in their new environment. The behavior of self-prevention illustrates how the elderly migrants managed themselves. Additionally, if the family members can understand the self-prevention, they will understand the behavior and the needs of the elderly migrants, which are related to their quality of life.

\section{Methodology}

This article presents the qualitative research by using a narrative approach and collected data from storytellers in different stories and situations. It focused on meanings that are embedded in the discourses. This approach is the process of human perception that is used to create the meaning of past events in life. Selection and removal of events to compose a continuous story starting from the base of the story results in the future appropriate to the cause and factors relating to a natural progression. Thus, creating the meaning of life with the dimensions of time, so the research story can access the meaning everyday experience of people (Bruner, 1986). 
This research encompassed one town, found in the surroundings of Khon Kaen city, in the northeastern region of Thailand. In-depth interviews were conducted with 16 elderly migrants. The participants were selected according to the following inclusion criteria: (i) aged over 60 years old when relocating from their original town to KhonKaen city, (ii) they had to have lived in Khon Kaen city for at least 6 months, and (iii) were in good health. Research believes that the elderly migrants are healthy, there should be more self prevention than the elderly migrants tack care of the household member. Initial contact was usually made by the researcher: the participant was asked to participate in the study and they would consent to be interviewed. The period of data collection was August 2017. This research was reviewed by the KhonKaen University human ethics committee, number HE603003.

Data was analyzedby thematic analysis method and took five steps including: checking the completeness of a story from an interview, looking for the focus of the studies, types of relationship in the stories, analysis of the meaning of the action that occurs and, interpreting and rewriting by the researcher (Riessman, 2008).

\section{Results and Discussion}

The context of the urban area "Lam Duan village" is located in Muang District, KhonKaen province. KhonKaen is a regional economic center for northeastern region. The village has a long history, being approximately 140 years old, and is only 7 kilometers from KhonKaen city thenearst municipal area. It is an outstanding village in terms of its location because the main roadfor regional and international transportation is located right in the middle of the village, as a result of the KhonKaen Development Project in accordance with the government's policy since 1992.People living in the village are seen to be both original and migrants. The original villagers work in agriculture and the service sectorwhereas the migrant villagers work in other sectors, such asbuilder, shoemaker, and barber. In terms of the social and culture aspects, they all abide by religious principles and traditions.

The urbanization of Lam Duan villageis the result of the $7^{\text {th }}$ National Economic and Social Development Plan, to turn KhonKaen into a center of business and industry. Therefore, the expansion of KhonKaen city affected the rural areas nearby. More people moved from downtown into the suburbs, and many migrants came to the city and bought a house on a housing estate or built on land during 1993-1997. It was found that there were 19 housing estates in Lam Duan village, which was higher than other areas in the province. Moreover, the offices of government's organizations and private sector companies were constructed in the village, such as a military camp, Office of Agricultural Research and Development, schools, and the Ban Uea Athon Khon Kaen housing project. They contributed to the investment and development of infrastructure such as electricity, water, public transportation, telecommunication, and medical services for villagers.

These factors pulled people from outside to relocate in the village, to live or work. The migration statistics showed that this village had a high incidence of movement when compared to other villages in the same province. There were 4,801 immigrants in 2012, 4,260 immigrants in 2013, 4,104 immigrants in 2014, 4,070 immigrants in 2015, and 4,310 immigrants in 2016 (Department of Local Administration Ministry of Interior, 2015). There were annually approximate 20 - 40 immigrants who were over 60 years old. The study found that there were several reasons why the elderly moved to the village; to live with their children, to work in both government and private organizations, and 
to receive medical services. Many elderly immigrants came from rural areas in Khon Kaen province, or from nearby provinces.

The relocation of all ages, during the past years, reflected that this village was an important destination according to its infrastructure and social structure which supports people's lives. These were the structural conditions that attracted people to come to the village and made it a destination for their lives.

Self-prevention is a way of trying to maintain one's dignity. Prevent the threat of failure. It's a way to help people keep their balance and ability to adapt to their own environment. In this study, it was found that there are four types of self-prevention in elderly migrants as follows:

\section{Denial of the Transition to Old Age and Refusal to be a Dependent Elder}

Migration at an elderly stage was a self-acceptance that the life would not be abandoned. They had relatives who were able to look after them. However, when elderly migrants moved in with their relatives, they did not just stay still and receive the care they deserved, but in return they helped with the household chores. The elderly migrants also considered themselves to be healthy, thus; there was no problem after moving because they were able to look after themselves. This was shown in the statement of a 73-year-old male migrant who moved to live with his daughter 5 years ago. He stated that:

"I didn't really get sick, still healthy... some might not be as healthy and could not help themselves so they had to rely on their children."

(Man, aged 73)

Apart from claiming that they were perfectly healthy and using that to deny the help of their relatives, this research also found that some of the elderly migrants used their accumulated capital to generate income for themselves, in other words, to become an elderly worker. For example, using their weaving skills, in bamboo or plastic fiber, to make utensils such as nets or mats. The expression of the elderly migrants in this way was associated with the thought that had been embedded that elderly people always relied on other people (Hooyman and Kiyak, 2002). Thus, being an elderly worker who had activities, took care of themselves, and did not rely on their relatives, were acts against the stated thought. Nonetheless, most of the elderly migrants in this research took on a role of being an elderly worker within the household. A 67-year-old female migrant, who had lived with her daughter and her grandchildren for 3 years, explained her daily routine as;

"... Here, I cook for them and do their laundry because my daughter has to work and she has no time. I have two granddaughters, one in Grade 7, one in Grade 4 and a baby granddaughter. I also cook for them and help them get ready for school."

(Woman, aged 74)

This demonstrated that this elderly female migrant did something when living with her family; she tried to take responsibility in the house and used her knowledge. This finding was similar to the finding of a study by Wongprom et al. (2015) that the elderly have kinds of work that are appropriate for their age and physical capacity. Examples of this kind of work are handicrafts. However, the statement related to the 2016 labour force survey that the number of elderly workers tended to 
increase from 2014 onwards. In 2016, 36.8\% of older persons were elderly workers. Especially,the elderly peoplein Northeastern Thailand, where most ofthe elderly workers are concentrated. Most elderly workers were in the agricultural sector and fishing industry (NSO, 2016). This information emphasizes that elderly people tended to be workers. In addition, the government should have regulations to support the elderly. This concludes that the elderly migrants tried to deny the transition to old age and refused to become dependent elders. They showed that they could take care of themselves to tell the family that "they were not old yet". At the same time, elderly migrants used their health to alleviate responsibility in the household by doing household chores in order to feel that they were important and had a role or status to be able to live in the household. This finding was similar to the findings of a study by Aramwiroj et al. (2011) thatthe elderly with their own role and household members who accepted them are well adjusted.

\section{Perceiving by Physical Limitation}

Perceiving by physical limitation; the elderly migrants used techniques to continue their life activities, both social and religious, in the same way as the elderly in the city. From the interview, it was found that the elderly immigrants realized their own limitations regarding health, living, and work. After moving to an urban area, they learnt how to resolve their limitations by participating in activities. The study found that there were 3-4 immigrants who used the perceiving by physical limitation of them. According to a 63-year-old male who applied this technique.

He was an immigrant who came to live with his son, an antiquarian, in a rented house. He came from Amphoe Penn, Udon Thani province, which is located 132 kilometers away. He was a farmer and had three children but no experience of moving to other places. This was the first time in his life that he had moved from his hometown. Despite being 'heavyset' he had good health that could walk to the shop in the village and perform his daily activities well. The reason for his relocation was due to the loss of his wife, so he was left to live alone in Amphoe Penn. Consequently, his son, who worked in Khon Kaen, asked him to move and live with him. The elderly migrant had been living in his 'new' village for three years. He accepted that he did not have the opportunity to go out to meet othervillagers. This was because he had to take care of the house while his son went for work early morning to the evening. He ceased his famer's lifestyle to undertake housework, such as cleaning.

He usually stayed at home so he did not have a chance to develop relationships with villagers because he looked after his son. However, he sometimes contributed to the village's activities, for instance, the village shrine worship ceremony, by donating money instead of participating. The elderly migrants realized their limitations and tried to grasp this divide by pushing themselves into activities or by trying to follow a life similar to the elderly in the village also, cultural context included social and religious activities, relationship with the community and family relationships, which support the cultural contexts of living in a community (Rojpaisarnkit,2016)

They fought against the concept of aging being dependent or relying on their children by doing housework, even though they had never done it before, in order to help their children. Some also had a hobby to earn some money. Nevertheless, they abided by the social structure of the village by donating to its activities. Therefore, these techniques of the elderly migrants made them feel that they were a part of the village and they could live happily within the community so, the elderly reinterprets and re-formulate their circumstances and related feelings. They positively reinterpret and exercise self-control over their feelings about needing help (Folkman \& Lazarus, 1988). The social 
support can help the person is a group of society which may help the person has a healthy body and mind (House, 2001).

\section{Life Goal Changing}

Due to migration, the elderly migrants had to change their role and lower their status to be just a supporter in the household because they had someone else responsible for household expenses such as electricity, water, and food. This meantthe elderly migrants did not have to be responsible forthe expenses, which was different from before they moved out of their area, where they were responsible for all expenses. However, there were some expenses that the elderly migrants had, for example, buying food, making merit, donating and taking part in social activities (this mostly occurred with elderly migrants who had lived in the urban area for more than 5 years). Their main source of income came from living allowance from the government and money from household members (both who lived together and who did not). This statement is supported by the National Statistical Office (2014) which stated that $36.7 \%$ of elderly migrants' income came from their children and $33.9 \%$ was from their own work; $14.8 \%$ from the government living allowance; $4.9 \%$ from their pensions; $4.3 \%$ from their spouses; 3.9\% from savings interest, and 1.5\% form other (NSO, 2015).

Many elderly migrants felt that living with their relatives was worth more than the money they got from the relatives. This statement was related to the study of the cause of migration by Koschasan (2014). It explained the reason why elderly migrate was because their children or relatives wanted them to stay close to the family, which was different to migrant workers who focused on the economic aspects (Chamratritthirong et al., 1995). In addition, the elderly who moved in to the urban area did not want anything more than to spendtime with their family. A 73-year-old male migrant, who migrated with his spouse to stay with their daughter for the past 10 years, stated that.

"In my opinion, I am so happy right now. As a human being we do not want to rely so much on money, just having food on the table every day is enough. That is because I do not think that I want to go to places or buy expensive things. I do not think about that at all because we are old. We eat to live and my daughter did not suffer. If I want to eat something, she will buy it for me."

(Man, aged 73)

According to the above statement, elderly migrants were happy to be with their family and did not want anything,or to receive special care from theirhousehold members. The fact they were close to the family and had someone taking care of them was like having an emotional support which increased their self-confidence and can be a link between their mind and feelings (Thepsiri, 2012). In addition, household members played an important role in making elderlymigrants behappy (Bunyanuphong et al, 1990). Also, household members took care of elderly migrants, made them feel more secure, and so they could face any obstacles that they might have to face (Riggo, 1968).

Apart from not wanting anything more than being close to the family, elderly migrants adjustedto the relationship among household members by organizing their relationship. This new relationship developed after migration by defining their new role and status in order to live peacefully with the other household members. An example of organizing a relationship was a 67-year-old female migrant who moved in with her son and his family, living in the same house for the past 2 years. She explained how she organized her relationship with her family: 
"I am not making a fuss for my son and his family and that makes me happy. If I keep nagging them, it will be me who is unhappy. Something does not need to be said, so that my son will not have to worry. One side his mother; another side is his wife, how can I make him choose? I never think about it. He can do whatever he wants as long as he is a good person."

(Woman, aged 67)

This statement showed that this elderly female migrant organized her role as a mother to her son, a mother-in-law to her daughter-in-law and as a grandmother to her grandchild by trying not to bother her son with problems. She kept what bothered her, and something that might cause a fight between her son and her daughter-in-law, to herself and had a good attitude towards the household members. This illustrated that elderly migrants used a self-prevention by changing their goal in life and being happy with what they had as well as organizing a relationship between themselves and the household members. These things helped elderly migrants feel important and happy when living with their relatives. Interestingly the elderly will understand and accept the actions and opinions of others, including having confidence in their own actions, an interesting relationship with other people, and a more profound relationship with kin. Meanwhile, there is more privacy. Understanding the differences between themselves and their roles, despite a broad call to discard theirobligations, the elderly are adjusted to maintain a role on the understanding of a successful life (Tornstam, 1989 in Wadensten, 2005).

\section{Anti-Fear}

Although elderly migrants werelooked after by household members, they still rejected their help in some aspects for example, using their still healthy bodies to alleviate some of the tasks in the household.However, in reality elderly migrants acknowledged that they had some limitations in terms of their health and income. It was found that they tried to deny the truth by trying to do somethings which other household members did not want them to do, such as working or driving a car. According to a 65-year-old male migrant who lived with his wife and her daughter in a rented house for 2 years, he stated that:

"...if my wife did not look after me, I would go alone. If I could not work, I would just keep walking and if I were hungry, I would not eat. I would just let my body be skinny. I think we have everything in our life. I will turn my phone off and not tell anyone where I am going. These thoughts are always on my mind. They have a rest home and someone will have to look after me. That is quite a responsibility."

(Man, aged 65)

This elderly migrant's perspective suggestedthat he did not want to be under someone's responsibility and did not want to be a dependent elder. He wanted to be independent and to choose the rest of his life by himself. This was the rejection of a government policy which was imposed to have some regulation to take care of older persons and the social system in which relatives must look after the elderly. The elderly acknowledged their own thoughts to fight against their fear and concerns of their lifestyle. In the study of Litwak and Longino (1987), titled 'Migration Patterns Among the Elderly: a developmental Perspective' it was found that the elderly who were capable of helping themselves tended to migrate without considering if there were any family members or relatives at the destination. On the other hand, the elderly who were capable of looking after themselves 
acknowledged their limitations in everyday life. This group of elderly people would migrate to where they had family, relatives, or moved into a rest home. The study of Kim et al.(2003) concerning a middle class elderly, aged 45 years old and above, in Seoul, South Korea when selecting their retirement home, it wasfound that this group chose a house not far from Seoul with easy access to the suburb area with a nice environment, easy access to facilities, fitness equipment and medical facilities. Both of the studies showed that elderly people can be independent and had the right to make a decision for themselves. Therefore, in order to support them in the transition of age process, society had to change their attitude towards older people, and that this transition was just another stage of life, not a dependent age, but they are still capable of managing themselves as well as benefiting their family and communities.

\section{Conclusion}

There are four types of self-prevention in this study; they are a denial of the transition to old, perceiving by physical limitation, life goal changing, and anti-fear. The behavior self-prevention these are related to the daily activities of the elderly migrants

The denial of the transition to old and perceiving by physical limitation of the elderly migrants was a relationship with roles and activity in daily life, for example, chores housework, food preparation, and being a babysitter. Even though the elderly migrants must change their role from being the head of the family to become a normal member, having a role in the family makes the older person feel superior and proud to confirm that it is not dependent household members into a single party. But still, with the help of household members back. Nonetheless, the role of elderly migrants depends on their self-esteem (Roscow, 1985 in Jenaobrom, 1991). On the same pace the Roy adaptation model theory in role function model (Roy \& Andrew, 1991). The elderly migrant is to modify the rules in order to make themselves acceptable to the household members and can show a new role is very efficient. The elderly migrants who have a role in the family are persons who are able to take care of themselves well. According to the activity theory of Robert Havighurst (1968), the elderly who enjoy doing activities are active, happy, and lively. They are proud of themselves and able to adapt to the surroundings well. The elderly will be happy to have activities with friends and people of all ages, mostly the elderly group. They were at the point of knowledge or the potential self (Saengtong, 2018). However, the participation in activates is based on the physical state of the elderly (Urairat \& Sabiying, 2018).

Furthermore, the second self-prevention behavior which involves elderly migrants is related to their thoughts and practice in the household. The elderly migrants who can adapt themselves in the household help maintain the relationship among household members. In addition, many elderly migrants realize their limitations, for example, they spend time alone, which make them feel relaxed. The result of the study supported the disengagement theory of Elaine Cumming and William Henry (1961). It was customary that the older persons decrease their roles in society to avoid the pressure and stress from their surroundings by withdrawing themselves from society. They were willing to have more time for relationships with family members and for relaxation in congruence with then explain the theory of adaptation model of Roy showed. The elderly migrants are adapted to achieve the dependency between the self with the household members, they feel secure in the living (Roy \& Andrew, 1991). The final self-prevention is an anti-fear behavior which is related to self-management of the elderly migrants. Being an old person is one of the changing processes of life. Many elderlies prepare themselves by having plans after retirement in order to avoid the fear of being elderly. This 
links with continuity theory in making adaptive choices, middle-aged and older adults attempt to preserve and maintain existing internal and external structures (Atchlry, 1989) that the elderly seek a new role in society to replace their old role and they adapt themselves continually in a new environment. However, in the perception of sociologists, the elderly who change their lives after moving in with a family reflect their strength and independence. They showed that they were able to learn new things and adapted to new surroundings. In the future, the elderly will be the main population in the world. There will be more and more elderly migrants; therefore, the involved organizations should be concerned about this. Nevertheless, the anti-fear behavior of elderly migrants caused by attention to the thinking and belief of the elderly migrants in which Roy calls this the self-concept model in personal self (Roy \& Andrew, 1991). Which is the beliefs and feelings about themselves at one time.

\section{Acknowledgements}

I would like to thank you for the graduate school, KhonKaen University, the Royal Golden Jubilee Ph.D. Program for academic support, and all key informants for this research.

\section{Reference}

Atchlry, R. (1989). A Continuity Theory of Normal Aging. The Gerontologist, 29 (2):183-190.

Aramwiroj, M., Chaikoolvatana, A., Suwanaprt, N., and Chananill Y. (2011). The Self-Adjustment and Social Supports of Elderly in Municipality, UbonRatchathani. Srinagarind Medical Journal, 26(3):196-206.

Bruner, J. (1986). Actual minds, possible worlds. Cambridge, MA: Harvard University Press.

Bunyanuphong, K., Bunyanuphong, S., and Chanta, S. (1990). The Life of the Elderly in Chiang Mai Province. Social Research Institute, Chiang Mai University.

Riesman, C. K. (2008). Narrative methods for the human sciences. CA, USA: SAGE Publications. Chamratrithirong, A., Archavanitkul, K., Richter, K., Guest, P., Thongthai, V., Boonchalaksi, W., Piriyathamwong, N., and Vong-Ek, P. (1995). National Migration Survey of Thailand. Nakhon Pathom, Thailand: Mahidol University, Institute for Population and Social Research [IPSR].

Chimmamee, M. (2014). Migration, Human Capitalization and Migration Plan of MigrantsLabour in Thailand. A dissertation Submitted in Partial Fulfillment of the Requirements for the degree of doctor of Philosophy Program in Demography College of Population Studies Chulalongkorn University.

Chanpueksa, P. (1994). Relationship between Personality, Social Engagement and Life Satisfaction of Thai Elderly in Bangkok. A Thesis Submitted in Partial Fulfillment of the Requirements for the degree of Master of Applied Behavioral Science Research Srinakharinwirot University.

Department of Local Administration Ministry of Interior. (2015). Statistics report on moving data year 2015. http://stat.bora.dopa.go.

Duangkaew, S. (2015). Lifestyle Migration of Japanese: A Case Study of Retired Japanese in Chiang Mai Province, Thailand. Japanese Studies Association of Thailand, 5 (1): 35-52.

Elaine, C., William, E.H. (1961). Growing old, the process of disengagement. Publisher, Basic Books. Eugene, L., Charles, F., and Longino, Jr.(1987). Migration Patterns Among the Elderly: A Developmental Perspective. The Gerontologist, 27 (3): 266-272. 
Foundation of Thai Gerontology Research and Development institute. (2013). Situation of the Thai elderly 2013.Bangkok, Thailand: Foundation of Thai Gerontology Research and Development institute.

Havighurst, R. J. (1968). Personality and patterns of aging. The Gerontologist,8 (1): 20-23.

Hooyman, N. R., and Kiyak, H. A. (2002). Social gerontology: A multidisciplinary perspective ( $6^{\text {th }}$ edition). Boston: Allyn and Bacon.

House, J. S. (2001). Social isolation kills, but how and why. Psychosomatic Medicine, $63: 273-274$. Jampaklay, A. (2013). Labor Migration and its Impacts on Family and Children in the ASEAN Community: Gains and Losses. Nakhon Pathom,Thailand: Mahidol University, Institute for Population and Social Research [IPSR].

Jenaobrom, S. (1991). Gerontology. Bangkok, Thailand: Faculty of Education, Chulalongkorn University.

Kaplan, L. D., Chahine, M. T., Susskind, J., and Searl, J. E. (1977). Spectral band passes for a high precision satellite sounder. Applied Optics,16 (2): 322-325.

Kim, O.-H., Kim, H.-B., Kim, W. G. (2003). Impacts of seiner Citizens 'Lifestyle on Their Choices of Elderly Housing. Journal of Consumer Marketing, 20 (3): 210-226.

Koschasan, T. (2014). In-migration and Adjustment of the Elderly in Chiang Mai Municipality. A Thesis Submitted in Partial Fulfillment of the Requirements for the degree of Master of Science (Geography) Chiang Mai University.

Rojpaisarnkit, K. (2016). Factors Influencing Well-Being in the Elderly Living in the Rural Areas of Easter Thailand. International Journal of Behavioral Science,12 (2):31-50.

Lee, E. S. (1966). A theory of migration. Demography, 3(1): 47 -57.

Liamputtong, P. (2014). Contemporary socio-cultural and political perspectives in Thailand. Dordrecht: Springer.

National Statistical Office. (2015). the 2014 survey of the older persons in Thailand, Bangkok, Thailand. Bangkok: National Statistical, Ministry of Information and Communication Technology Publisher.

Office of the National Economic and Social Development Board. (2016). The Eleventh national economic and social development plan (2012-2016). Bangkok, Thailand: National Economic and Social Development Board office of the Prime Minister.

Porapakkham, Y., Atibobhi S. (2000). Health conditions and tendency of the elderly population. Nonthaburi, Thailand: Health System Research Institute.

Prasartkul, P. (2000). Demography: Substantive Study on Human Population. Nakhon Pathom, Thailand: Mahidol University, Institute for Population and Social Research [IPSR].

Riggio, R. E. (1986). Assessment of basic social skills. Journal of Personality and Social Psychology, 51 (3): 649-660.

Roy, S. C., Andrew H. A. (1991). The Roy Adaptation Model: The Definitive Statement. Norwalk: Appleton and Lange.

Saentong, J. (2018). Aging society (Complete Aged): The elderly condition of good quality. Rusamilae journal, 38 (10): 1-23.

Suton, L. (2008). Application of the Elderly Wisdom to support the programs of Senior Citizens Club: A Case Study in Senior Citizens Council of Thailand (SCCT). A Thesis Submitted in Partial Fulfillment of the Requirements for the degree of Master of Social Welfare Administration and Policy Thammasat University. 
Thepsiri, P. (2012). Quality of Life of the Elderly in Banna District Nakhonnayok Province. A Thesis Submitted in Partial Fulfillment of the Requirements for the degree of Master of Public Administration. Krirk University.

United Nations. (2002). World Population Ageing 1950 - 2050. New York: United.

Urairat, M., Sabiying, M. (2018). Self-esteem in the elderly: A case study of an elderly aids foundation in Songkhla province. Rusamilae journal, 38(10): 29-44.

Wadensten, B. (2005). Introducing Older People to the Theory of Gerotranscendence. Journal of Advanced Nursing, 52 (4): 381-388.

Wongprom, J., Yenbarung, T., Jongwutiwes, K., Chaowagul, M., and Maneerat, S. (2015).The research on Mechanisms for Promotion of Employment of Older Persons who are Informal Laborers KhonKaen, Thailand: KhonKaen University, Research and Development Institute. 